\title{
The Employability Status of Makerere University Graduates
}

\author{
Ssembatya A. Vincent ${ }^{1}$, Ngobi Kiwanuka Robert ${ }^{2}$ \\ 1. Quality Assurance Directorate, Makerere University P.O.Box 7062 Kampala \\ 2. P.O. Box 24911 Kampala (Permanent Address)
}

The research is financed by Sida (Sponsoring information)

\begin{abstract}
The study applied the pathways approach, Survey Monkey and Snowballing techniques to ascertain the employability status of the 2012 graduates of Makerere University. The majority of the graduates were employed in the public sector on full time basis. The young graduates, however, favorably competed for entry job opportunities with the mature graduates. A reasonable number of the 2012 Makerere University graduates were engaged in self-employment as an avenue for addressing the problem of graduate unemployment in Uganda.
\end{abstract}

Key words: Graduate unemployment, Makerere University, Tracer studies, Pathways

DOI: $10.7176 / J E P / 10-6-11$

\section{Introduction}

Makerere University is the premium public university in Uganda holding about $20 \%$ of the total higher education enrolment. The university has graduated more than 180,000 graduates since 1970 . The university currently graduates a minimum of 10,000 graduates annually attributed to its diverse academic programs that include: 107 undergraduate programs and 150 graduate programs. Sixty percent of the students are, however, enrolled in the Arts, Humanities and Business programs with less than $25 \%$ of its students enrolled on graduate programs. Its annual doctoral production has currently stabilized at a minimum of 50 doctorates. The university uses a number of feedback mechanisms for continual improvement of its tripartite functions (teaching \& learning, research \& publication and community engagement) including but not limited to external examinations, peer reviews, selfassessment, benchmarking, employer expectation surveys and graduate destination surveys/tracer studies.

Makerere University has a long tradition of conducting graduate tracer studies (Kirumira \& Bategenya, 2003, Ndungutse, 2005, Mayanja et al, 1999, Lutwama \& Kigongo-Bukenya, 2004). The university conducted a tracer study for its 2012 graduates in order to map the complex transition of its graduates from education levels that merited their admission through the university to the world of work. Tracer studies are one of the several monitoring mechanisms for getting feedback from university graduates and or their employers relating to "fitness for purpose", relevance, strengths, weaknesses and areas for improvement of academic programs offered by universities (Oseifuah, Gyekye, Noviskwadzo \& Vukor-Quashire, 2014). Panel tracer studies are, however, preferred in which the same cohort is traced and surveyed more than once. The approach introduces reliability in the results and progressive dimensions regarding graduates engagements, mobility, transition and experiences (Syafid \& Fikawati, 2010). Longitudinal graduate surveys can provide evidence about the extent to which graduates are using the knowledge \& skills acquired in their courses of study and how employers require \& utilize qualified graduates available to them (Blossdeld, 2009). Schomburg (2003), however, asserts that tracer studies provide essential feedback regarding the relevance of courses of study, labour market success of graduates, training quality, graduate skills \& knowledge adequacies and recommendations for training quality improvements.

The overall objective of the tracer study was therefore to triangulate the complex transition of the 2012 Makerere University graduates from secondary schools through university into work or unemployment. It specifically set out to investigate graduate destinations, transitions into higher qualifications, perceptions about transferable skills acquired during training and transition factors affecting the rate at which the graduates moved to the world of work. The tracer study did not include doctoral graduates largely due methodological differences required to trace doctorate holders.

\section{Conceptual Framework}

Graduate unemployment remains a social cancer in many developing countries. It results in a waste of resources spent on studies and reduces the quality of life \& self-esteem of the graduates. Although graduate unemployment is an empirical issue, in developing countries it is attributed to either the mismatch of skills imparted to graduates by higher education institutions \& those required by prospective employers and or the small size of the country economies that do not provide enough beginner jobs to enable fresh graduates to launch their career paths and professional growth. Graduate employability is further complicated by other social factors such as unequal 
access to employment opportunities, pre-work experiences, study disciplines, repute of training institutions and differences in employability attributes such as communication skills, team work, interpersonal relations, Information and Communication Technology skills, self-management etc (Harvey, 2001, Rosenburg, Heimler \& Morote, 2012).

Since finding a job after studies is one of the major objectives of graduates, failure to find one is a concern to a number of stakeholders including governments, higher education training institutions, prospective students and families of the graduates. Graduate tracer studies have hence become a useful feedback mechanism to higher education instructions to ascertain the employability status of their graduates, employer expectations of their graduates, relevance of courses of studies and further study progressions of graduates. Forging strong linkages between the universities and the world of work will hence make universities responsive to societal and professional needs of their graduates. This will be achieved by universities ensuring that the graduates they produce are: of the right type, equipped with appropriate knowledge, expertise \& skills so as to be able to meet the changing needs of the contemporary labour market (Martin, Lang-ay \& Guidangen, 2015).

Schomburg (2003) notes that graduate destination surveys /tracer studies are a tangible feedback mechanism for "analysis of the relationship between higher education and work". A model for analysis of the concept of tracer studies applicable to higher education suggested by Schomburg (2003) is illustrated in Figure 1.

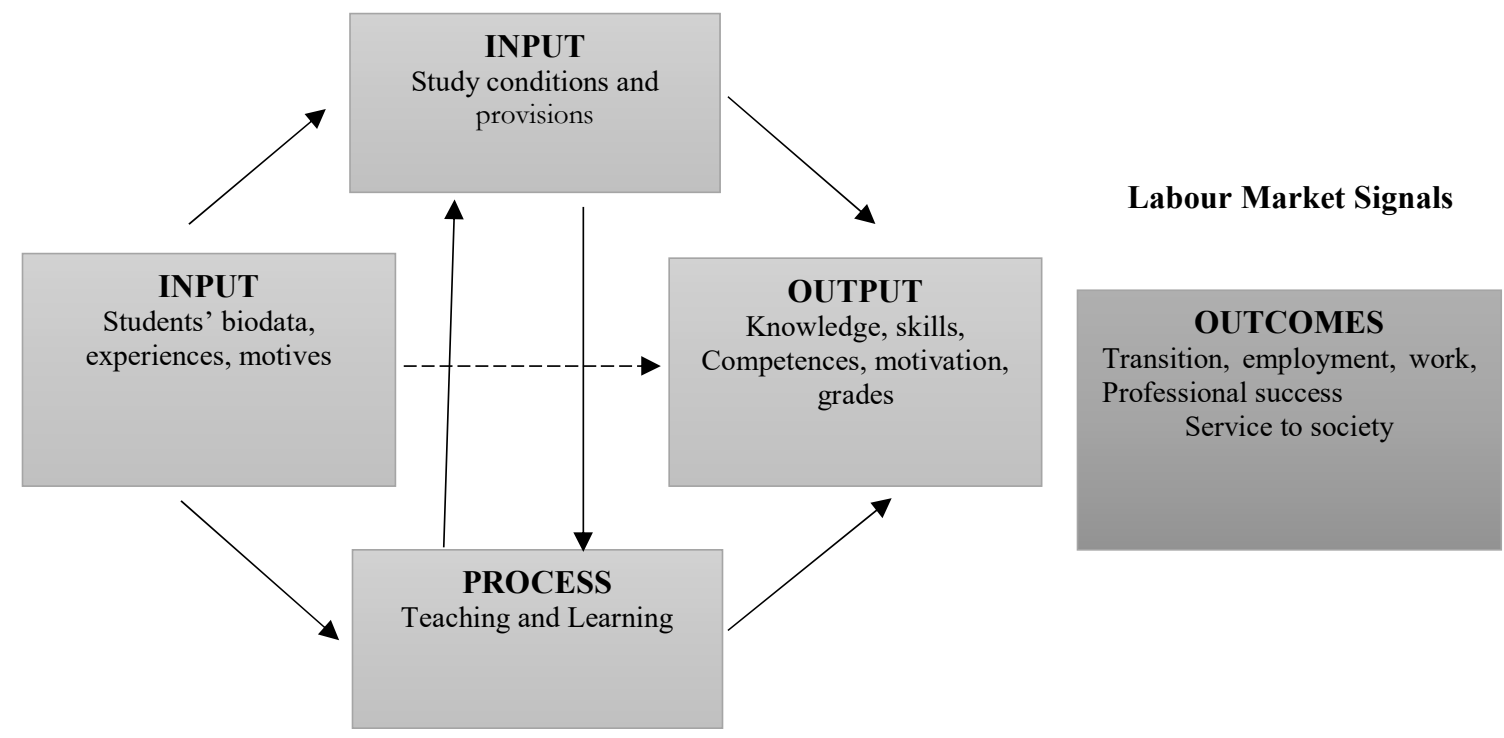

Figure 1: Model of Analysis in Higher Education Tracer Study.

Adopted from Harald Schomburg (2003) Handbook for Graduate Tracer Studies

Schomburg (2003) asserts that the retrospective views of graduates on higher education based on their career experiences, the extent to which they consider higher education training as either a waste or opportunity and how broad or narrow the knowledge imparted to them in comparison to occupational tasks are some of the key areas graduate trace studies unravel. Graduate tracer studies however, need to be timed carefully to ensure that sufficient time has elapsed to provide tangible and informative feedback (Saide, 2011).

\section{Literature Review}

At international level, the most consistent research on tracer studies is attributed to Schomberg and Teicher (2006). In Africa, Mugabushaka, Teicher and Schomberg (2003) revealed high unemployment rates (10\%) and low transitions from higher education institutions to work among graduates of six African countries for the 199697 period. The causal factors for graduate unemployment in Africa range from inappropriate institutional \& subject choices, imperfect information flows including poor career guidance, poor academic grades to the shrinking civil service. "Arts and Social Sciences" discipline graduates are candidates for high unemployment rates signaling difficulties in finding first employment opportunities upon graduation.

A number of trace studies have been conducted by universities in Uganda with a common objective of establishing whether their graduates were employed in their fields of specialty or not. The National Council for Higher Education, a higher education regulatory agency in Uganda, occasionally conducts tracer studies. At 
institutional level, Makerere University conducted a number of tracer studies focusing largely on graduates of its former faculties (Kirumira \& Bategenya, 2003, Ndungutse, 2005, Mayanja et al, 1999).

Lutwama and Kigongo-Bukenya (2004) traced the 1995-1999 graduates of the East African School of Library and Information Science (EASLIS) academic program, hosted at Makerere University. The majority of the graduates $(65 \%)$ of the graduates were employed in academic traditional libraries as Librarians, Information Officers or Records Managers. The graduates were mainly employed in universities with Makerere University, Mbarara University of Science \& Technology and Kyambogo Universities as major employers since they have well established libraries. Competence, innovation, flexibility to change, self-supervision, and personality were rated highly as skills most required to enhance the employability of EASLIS graduates working in Uganda. In addition, $55 \%$ of the respondents recommended for the review of the curriculum to reflect the emerging information needs with more emphasis on ICT since they asserted that the then curriculum was slanted towards traditional libraries.

Ssembatya and Ngobi (2014) have, however, conducted comprehensive tracer studies at Makerere University targeting all its nine colleges and the school of law. The focus of the tracer study was the doctoral graduates of the period, 2000-2012. Makerere University had more doubled its annual doctoral production from 23 in 2000 to 61 in 2012. More than 300 doctorates were awarded during the 2000-2012, period. Most of the doctorates were from the science disciplines with emerging capacities from the College of Health Sciences. The majority (97\%) of the doctoral graduates were employed in fields related to their training. There is, however, an impending challenge in retaining doctorates trained at Makerere University since $92 \%$ of the respondents indicated they would leave Uganda once an opportunity was availed. Low salaries and benefits were the major demotivating factors. Only $23 \%$ of the doctoral graduates were female mirroring the low representation of females in leadership and seniority at decision making bodies at the university. The study recommended for an increase in doctoral production in Uganda so as to meet the increased demand for doctorates attributed to the expanding: higher education sub-sector, research institutions and the emerging system of innovations.

Egesah, Wahome, Langat \& Wishitemi (2014) traced Moi University 2009 first degree graduates. The graduates $(70 \%)$ were employed in their lines of study and $56 \%$ of them were employed in the private sector while $25 \%$ of the respondents were employed in the public sector. Only $21 \%$ of the graduates found employment opportunities through work placements, internships and attachments. The course of study was the major consideration (46\%) by employers in offering employment opportunities to the first time job seekers. In a closely related study, Kiliswa, Udoto \& Konyango (2016) sought to establish the employability status of the 2008 cohort of graduates of the B.Sc. in Agricultural Education and Extension (B.Sc AGED \& EXTN) of Egerton University. The majority $(61.2 \%)$ of the graduates were employed by the Teachers Service Commission as teachers of Agriculture and Biology followed by the private sector (14\%). The distribution of employed graduates is attributed to the fact that the B.Sc AGED \& EXTN degree program is a diverse course and hence exposes its graduates to various career opportunities.

Rojas and Rojas (2016) revealed that the majority (43.02\%) of education graduates of Cebu Technological University graduates were employed on permanent terms and $33.18 \%$ on contractual terms in their fields of study. They were mainly employed by government schools. Forty four percent of the graduates acquired jobs as walkin applicants and only six percent through the university placement office. The personality of the graduates was the prime (31\%) contributing factor to acquiring employment while the field of study was second with $16 \%$. Good human relations therefore matters a lot in teaching since students learn better under the instruction of a pleasant teacher.

The University of West Indies (2010) indicated that employment rates of graduates fell from $91 \%$ in 2007 to $84 \%$ in 2008 . The dominant employer of the graduates was the public sector though there were considerable differences in the employability of graduates. High employment rates were observed in the faculties of education and medical sciences while humanities registered high unemployment rates. $47.5 \%$ of the graduates were employed in jobs closely aligned to their fields of study. Thirty one percent of the respondents had enrolled for further studies in the same field or within the broader discipline of their first degree. There was a $6 \%$ increase in the number of graduates who opted to study and work at the same time in 2008 compared to 2007.

Celis, Festijo \& Cueto (2013) sought to ascertain the employability status of graduates of Hotel and Restaurant Management (HRM) of Lyceum of Philippines University (LPU) for the period 2005-2009. Majority (81.5\%) of 
the graduates got formal employment mainly in the Philippines within less than two years after graduation and were mainly employed in their fields of specialty. The findings are similar for earlier cohorts of 2001-2005 traced by Menez \& Ylagan (2011) who revealed a 91.3\% employability for HRM graduates. Salary and benefits were the major $(39.7 \%)$ considerations for acceptance of job offers by the graduates. Perseverance was a major attribute in meeting the job requirements for HRM graduates. The respondents asserted that both the general and professional courses were relevant, however, human relations and communication skills were the most useful competencies required in their places of work.

Wanya (2014) revealed that the majority (81.9\%) of the Bsc. Information Technology graduates of Cagayan State University at Lal-Lo found jobs in areas not related to areas of specialty because there were few job vacancies in their fields of study. Two percent of self-employed graduates started businesses related to their course of study. Mismatch of job requirements with educational qualifications was ranked as the second hindrance encountered in finding suitable employment opportunities by the graduates. Scholastic standing followed by personality were the most important factors in finding the first employment by the respondents. Salary was both a motivating (high salary) and demotivating (low salary) factor for graduate job seekers. The IT skills acquired by the respondents were useful in both private and public organisations where the graduates were employed.

Oseifuah, Gyekye, Novisikwadzo \& Vukor-Quashire (2014) applied the snowball technique to establish the employability status of the Bachelor of Commerce (BCOM) graduates of University of Venda. The majority $(54 \%)$ of the respondents were female perfectly mirroring the enrolment trends $(51 \%)$. Only $23 \%$ of the graduates were employed in the private sector yet it is considered the major employer in South Africa. Personality was a major factor in landing an accounting job opportunity. The BCOM program needed improvements in the following areas to increase the employability of the graduates: training in practical skills, use of computers in accountancy training and introduction of student internship. The major limitation of the study is that it did not seek the opinion of the unemployed graduates.

Maratas \& Campiseno (2018) set out to ascertain the popularity of courses of study offered by the Jose Rozal Memorial State University (JRMSU), Philippines among employers. The scope of the study was undergraduate 2010/11-2013/14 cohorts. Majority of the respondents were employed on contractual terms in industries and organizations related to education, wholesale \& retail trade, financial intermediation, manufacturing and public administration. Arts and Sciences $(83.3 \%)$ were the most popular disciplines among employers followed by engineering programs (64.3\%) in terms of employability of graduates. Among the unemployed, $40 \%$ revealed that there were no job openings in their fields of study. The respondents, $73.04 \%$ found jobs in their line of study and were satisfied with their employment conditions. Employed graduates (59.6\%) found jobs within 6-12 months after graduation. Only $1.3 \%$ of the respondents were self-employed. There were low $(16 \%)$ transition rates to higher qualifications among the graduates. There were gender biases with $52.4 \%$ of the employed respondents being male.

In a related study, Pacatanga (2016) traced graduates of the 2007-2014 cohorts of the Bs Criminology, Jose Rizal Memorial State University (JRMU) so as to determine their employability status. Most (59.14\%) of the respondents were employed in occupations related to criminology and found jobs within 1-2 years after graduation. Job prospects after graduation was the major consideration for choosing JRMU by the respondents. Salary and benefits were major considerations by $43.3 \%$ of the graduates in accepting their job offers. Lack of vacancies was cited as the main reason $(59.2 \%)$ for graduate unemployment. Ninety three percent of the respondents, however, asserted that internship or work experience were essential in securing the preferred jobs. Human relations were in addition rated as the most important competency that helped graduates to work and get along with others.

\section{Materials and Methods}

The study applied the pathways approach, Survey Monkey and Snowballing techniques to ascertain the employability status of the 2012 graduates of Makerere University. The questionnaire was a major a research instrument used in conducting the tracer study.

\subsection{Procedure for conducting the Tracer Study}

The tracer study for the 2012 cohort of Makerere University graduates followed four sequential generic 
procedures: compilation of sample framework, design of the questionnaire, administering the questionnaire and data capturing, cleaning \& analysis. The data for the sample frame was obtained from the University Registry. The sample for the tracer study was drawn from the population of graduates of Makerere University of the year 2012 with the exception of those awarded doctorates. A total of 11,022 degrees were awarded of which 42 were doctorates. Among the graduates, $46.7 \%$ were female. The degrees were awarded across 86 undergraduate programs; 87 Masters Programs; 7postgraduate diplomas and 8 undergraduate diplomas. The details of the sample frame of the respondents are highlighted in Table $\mathbf{1 .}$

\begin{tabular}{|l|l|l|l|}
\hline Table 1: Sample Frame showing number of 2012 graduates & Female & Male & Total \\
\hline & 154 & 105 & 259 \\
\hline Undergraduate Diplomas & 3 & 15 & 18 \\
\hline Postgraduate Diplomas & 4592 & 5079 & 9671 \\
\hline Bachelor's Degrees & 386 & 646 & 1032 \\
\hline Masters & & 366 \\
\hline
\end{tabular}

The questionnaire was designed focusing on the notion of the different pathways from study to work or unemployment, student \& parental educational backgrounds and desire for further studies. The questionnaire was chronological in nature and filtered responses to situational questions. The questionnaire also captured transition factors from university education to work such as levels of education of parents or guardians, career guidance received by students, participation in extra curriculum activities and internships or work placements undertaken by students prior to graduation. The questionnaire was pre-tested to 207 respondents and rolled out to a total of 4000 respondents using both the Survey Monkey and Snowballing techniques. The responses on the survey monkey were automatically captured electronically while research assistants physically administered the rest of the questionnaires. The two data sets were screened to avoid duplications and later merged for analysis. The original data set was used to validate the filled questionnaires returned by research assistants.

\section{Results}

\subsection{General Characteristics of Respondents}

The total number of respondents was 1961 against a target of 4000 representing $49 \%$ response rate. The response rate of $49 \%$ falls within the expected response rate of 30 to 60 percent recommended by Schomburg 2003 for graduate tracer studies. The size of the sample was $18 \%$ of the sample frame. Forty six percent of the respondents were female mirroring the gender distribution of the university. The majority of the respondents were aged 26-30 and they accessed the university mainly after completion of secondary school education. Close to $80 \%$ of the respondents were tuition-paying students, known as private students. $50 \%$ of the 2012 graduates studied at government aided secondary schools, however, the dominance of government aided schools for enrolment at Makerere University is continuously dwindling. Respondents are predominantly still unmarried and distribution was skewed towards humanities a perfect reflection of the enrolment trends at Makerere University. Mothers or female guardians of the respondents were more educated at Primary, Secondary and Certificate while the fathers or male guardians of the respondents were more educated at Diploma, Degree and Masters Levels. In this tracer study, 540 parents of the 1961 respondents were first-degree graduates whereas 61 parents had at least a Masters degrees. The study sought out to find out the education levels of the parents and or guardians of the respondents because the relationship between the education of the parents and student achievement has received attention by scholars. The involvement of parents in the education of their children starts from early childhood. Key transformative factors include the choice of schools, support with homework, creating safe home environments \& neighborhoods and playing inspirational roles to their children.

\subsection{Student Experiences while studying for the qualifications}

Makerere University gives opportunity to students to engage in a variety of intra and extra curricula activities to enrich the experiences of the students and to produce holistic graduates. In addition to being a conduit for useful feedback into curriculum, these activities provide hands on experiences and prospects for future employment. Extra-curricular activities like sports; cultural activities; religious and students' leadership engagements promote the general wellbeing of the students. Furthermore these activities promote the creation of teams and networks 
that may become useful springboards to social cohesion \& harmony in society and for some it turns out to be future careers. Table 2 provides a summary of how the respondents participated in intra and extra curricula activities at Makerere University.

Table 2: Students Intra and Extra Curricula Participation

\begin{tabular}{|l|l|l|l|}
\hline Activity & Yes & No & Undeclared \\
\hline Received Career Guidance & 1518 & 227 & 135 \\
\hline Participated in Supervised Internship & 1521 & 243 & 116 \\
\hline Program Required Completion of a Project & 655 & 887 & 338 \\
\hline Participation in Academic Associations & 591 & 6 & 1283 \\
\hline Participation in Sports & 294 & 7 & 1579 \\
\hline Participation in Cultural Organizations & 310 & 6 & 1564 \\
\hline Participation in Religious organizations & 334 & 5 & 1541 \\
\hline Participation in Student Leadership & 310 & 8 & 1562 \\
\hline
\end{tabular}

\subsection{Internship and Project Requirements}

The internship policy requires every student to accomplish a supervised internship program. Students are expected to write a project report on completion of the internship. Among the respondents in the tracer study, $78 \%$ indicated that they received supervised internship. Reasons for missing supervision for some respondents were not established in this survey. However, it is presumed that non participation in supervised internship is due to late release of funds, lack of placement, miscommunication between the student and supervisor.

The internship policy was in its formative stages by the time the respondents were undertaking their training. The implementation of the internship policy has been incremental, utilizing a base of programs that had internship requirements inscribed in their curriculum. The policy approved by the University Senate in July 2006 required discipline specific interpretation and inclusion of the internship component into the revised curricula. In addition massive sensitization was required for different stakeholders who included students, parents, university staff and industry. These stakeholders were on different learning curves. A successful internship program requires close collaboration between the university \& the industry, commitment on behalf of the student and adequate funding to last the duration of the internship period.

\subsection{Pathways to Employment}

The concept of pathways has attracted a lot of attention as a feedback mechanism used to ascertain the different transition possibilities to the world of work or no work by higher education graduates (Guthrie, Stanwick \& Karmel, 2008). Generic pathways for university graduates to the world of employment have been identified as journeys individual graduates take from the universities to work. The study adopted the description of the pathways that was used by the Cape Higher Education Consortium (CHEC, 2013) to explain the different routes that graduates follow while transiting from university to the world of work. The CHEC 2013 set out to determine levels of graduate employment \& unemployment and to understand the different pathways from university to work of the 2010 cohort of four universities in the Western Cape: Cape Peninsula University of Technology, University of Cape Town, Stellenbosch University and University of the Western Cape. The CHEC 2013 identifies seven pathways followed by university graduates to work:

1. Employed graduates who have entered the labor market for the first time after graduation at full employment;

2. Employed graduates who were employed prior to studying for the award of interest;

3. Self-employed graduates;

4. Unemployed graduates;

5. Continuing higher education training;

6. Graduate employees in informal sector;

7. Unemployed graduates not looking for work. 
The respondents of this study were classified within seven pathways as indicated in Table 3 .

\begin{tabular}{|l|c|}
\hline Table 3 :Pathways to Employment & Sub-Totals \\
\hline Fully employed graduates who entered the labor market for the first time & 1264 \\
\hline Graduates employed prior to studying for the qualification awarded & 241 \\
\hline Self-employed graduates & 239 \\
\hline Unemployed graduates looking for work & 252 \\
\hline Graduates continuing with higher education & 301 \\
\hline Graduates employed in the Informal Sector & 46 \\
\hline Unemployed graduates not looking for work & 22 \\
\hline
\end{tabular}

The total number of graduates in full employment who entered the labor market for the first time constituted the majority of the graduates (1264); more than 5 times those who were self-employed. The university encourages job creation by its graduates to address the problem of graduate and youth unemployment. The total number of graduates who indicated that they were fully employed (spent at least 40 hours a week on the same job) constituted $70 \%$ of the respondents. This category consists of both young and mature graduates who took up jobs before training for the award acquired in 2012. The total number of unemployed graduates was $18 \%$. The average graduate unemployment rate for low-income countries in Africa is 16\% (Friesenhahn, 2015). The implication is that the graduate unemployment rate of Makerere University graduates of 2012 was above the mean for graduate unemployment in Africa.

Working Full Time: This is one of the most curious parameters in this Tracer Study since it drives the objectives of higher education from the national standpoint of creating a knowledgeable and skilled human resource capital able to exploit and use resources gainfully and sustainably. The number of graduates who were working full time was 1308 of the 1961 respondents (67\%). Of the respondents working full time, 1076 (83\%) worked for the public sector. This indicates that graduate employment is strongly linked with public sector job opportunities. According to the Uganda Statistical Abstract (UBOS, 2013), 17,106 jobs were advertised in 2012. Among the respondents in this Tracer Study, 790 indicated that the source of their jobs was through advertisement representing $42 \%$ of the sources of information. Social Networking represented $13 \%$ as a source of information on employment whereas head hunting accounted for $7 \%$ as a source of information. Direct contact by the employers accounted for $8 \%$ while undisclosed sources contributed $30 \%$. Advertisements of job vacancies promotes transparency in the recruitment process of job seekers and should be encouraged for both public and private enterprises.

Most respondents had not obtained further qualifications by April 2015. This is not surprising as such qualifications require more time (more than 2 years) to accomplish. The majority of respondents would consider re- enrolling at Makerere University for further studies, however, the major obstacle to pursuing further studies by the respondents are financial related.

\subsection{Employers of Graduates}

The Public Sector in Uganda employed the majority of Makerere University graduates of the year 2012. In particular, 83\% of those fully employed worked for the Public Sector. Respondents in this survey were employed in 97 Government institutions including Makerere University. The leading employer in the Public Sector was Kampala Capital City Authority followed by Makerere University and the Ministry of Internal Affairs. The total number of Private Sector employers of the respondents was 720. The top employer in this category was MTN Uganda Limited followed by Equity Bank and Stanbic Bank respectively. The key players in the top ten were telecom companies, banks and Non-Governmental Organization (NGOs), namely, Watoto Child Care Ministries and Save the Children Fund.

\section{Conclusions}

The number of young graduates who were working full time was 1308 of the 1961 respondents $(67 \%)$. The fully employed graduates (spent at least 40 hours a week on the same job) constituted $70 \%$ of the respondents. This category consists of both young and mature graduates who took up jobs before training for the Award acquired in 2012. This implies that young graduates favorably competed with mature graduates for the entry job opportunities that were available. In a number of cases mature graduates have pre-study work experiences 
and usually out compete young graduates majorly in the private sector.

Of the respondents working full time, 1076 (83\%) worked for the public sector. This is indicates that graduate employment is strongly coupled with public sector job opportunities. This is a pointer to the fact that the private sector is still a small employer of university graduates in Uganda compared to countries like South Africa where the private sector is a significant employer of university graduates. The number of graduates in self-employment is small (241) implying that self-employment as solution to graduate unemployment is still in its infancy though it is highly fantasied by higher education policy makers. The aspect of graduate selfemployment needs to be critically addressed by sufficiently addressing the hindrances encountered by higher education graduates in the process of creating their own employment. Advertising was the major source of information on job opportunities representing $42 \%$ of the sources of information. The fact that a substantial number of graduates got jobs through advertisement in public media is a pointer that there could be some level of transparency in the public recruitment process.

The study, however, makes a number of recommendations including:

a) Matching of graduates with jobs is crucial in decreasing the graduate unemployment. University Industrial links need to be fortified through a comprehensive internship program. These linkages will in turn support the integration of stakeholder expectations into the curriculum of the university;

b) Most of the respondents acquired jobs through advertisements. Public and private sectors should be encouraged to advertise jobs in various media including the emerging social media;

c) Most respondents indicated the highest impediment to their pursuit of further Higher Education qualifications was lack of financial support. Government should consider increasing the funding of graduate studies to increase the transition rates from undergraduate to graduate studies;

d) Communication skills were ranked highest whereas entrepreneurial skills were ranked lowest as transferable skills. A cross-cutting course in entrepreneurial skills should be developed and embedded in curricula across disciplines; this course should include aspects of negotiation, analytical and decisionmaking skills and

e) Students should be encouraged to engage in personal development schemes to buttress the acquired transferable skills to meet the requirements at the world of work

\section{Reference}

Blossdeld, H.P. (2009) 'Methodological Advantages of Panel Studies: Designing the New National Educational Panel Study (NEPS) in Germany’. Journal for Educational Research Online. 1(1):10- 32.

Celis, M.C., Festijo, B., \& Cueto, A. (2013). Graduates' employability: A tracer study for Bachelor of Science in Hotel and Restaurant Management. Asian Academic Research Journal of Multidisciplinary. $\quad 1(11): 225-238$.

Egesah, O.B., Wahome, M., Langat, E.K, \& Wishitemi, B.E.L. (2014). University graduate tracer studies (UNITRACE): Methodological lessons and utilization of selected results in Kenya. Journal of International Academic Research for Multidisciplinary, 2(8):305-325.

Friesenhahn, I. (2015). Making Higher Education work for Africa: Facts and Figures.

Guthrie, H., Stanwick, J., \& Karmel, T. (2008). Pathways: Developing the skills of Australians workforce. National Centre for Vocational Education Research.

Harvey, L. (2001). Defining and measuring employability. Quality in Higher Education. 7(2): 97-109.

Kiliswa, I., Udoto, M.O., \& Kanyango, J.J.J.O. (2016). Tracer study of Bachelor of Science in Agriculture Education and Extension graduates-Class of 2008-Egerton University. Imperial Journal of Interdisciplinary Research. 2(8): 1080-1085.

Kirumira, E. and Bateganya, F., Where has all the education in Uganda gone: Employment outcomes among secondary school and university leavers, Institute of Development Studies, University of Sussex, August 2003.

Lutwama, E., \& Kigongo-Bukenya, I.M.N. (2004). A tracer study of the East African School of Library and Information Science graduates 1995-1999 working in Uganda. South African Journal of Libraries and Information Sciences. 70(2):99-109.

Maratas, N.O., \& Campiseno, J.S.R. (2018). Destination and employability of graduates of JRMSU: An Analysis. International Journal of Current Research. 10(05): 69236-69243.

Maratin, J.G.S, Lang-ay, P., L.D., Guidangen, J.S. (2015). Tracer study of 2009-2013 BA History graduates of the Kalinga-Apayao State College. International Journal of Advanced Research in Management and Social Sciences. 4(12): 197-214.

Mayanja, M.K., Nakayiwa-Mayega, F., Adebua, A., Kabuye, M.K., \& Kaase-Bwanga, E. (1999). Comprehensive study of Makerere University graduates of the faculties of Arts and Sciences.

Menez, Fe, \& Ylagan. (2016). A tracer study of LIS graduates at the University of Zululand, 2000- 2009.Paper 
presented at the $6^{\text {th }}$ Biennial PROLISSA Conference, Proteria, 9-11 ${ }^{\text {th }}$ March 2011.

Mugabushaka, A.M., Teicher, U., \& Schomburg, H. (20034). Failed or self-hindering prophecies? Employment experiences of African graduates in the 1990s. Journal of Higher Education in Africa. 1(1): 57-77.

Ndungutse, D. (2015). Tracer study for 1980-2001 graduates of Faculty of Medicine, Makerere University.

Oseifuah, E., K., Gyekye., A., B., Novisikwadzo, G., \& Vukor-Quashire., (2014). Bachelor of Commerce Programme and Employability of University of Venda graduates, South Africa. Journal of Economics and Behavioral Studies, 6 (4): 291-301.

Pacantanga, D.H.Q. (2016). Tracer study of Bs Criminology graduates of Jose Rizal Memorial State University. Journal of International Academic Research for Multidisciplinary, 4(2):240-252.

Rojas, T.T., \& Rojas, R., C. (2016). College of Education graduate tracer study (GTS): Boon or Bane?. European Scientific Journal, 12(16):63-78.

Rosenberg,S., Heimler, R., \& Morote, S. (2012). Basic employability skills: A triangular design approach. Education + Training. 54(1):7-20.

Schomburg, H. (2003). Handbook for Graduate Tracer Studies.

Schomburg, H., \& Teicher, U. (2006). Higher education and graduate employment in Europe. Results from graduate surveys from twelve countries. Higher Education Dynamics 15, Dorrecht, Springer.

Ssembatya, V.A \& Ngobi.K.R. (2014). Mapping the Careers and Mobility of Makerere University Doctoral Graduates. A tracer study on PhD Graduates of Makerere University 2000-2012.

Syafid, A., \& Fikawati, S, (2010). Tracer Study at University of Indonesia, 2012, Problems in the field and results dissemination. UNITRACE, WCHER-Kassel.

The University of West Indies (2010). Report on graduate tracer survey of first degree graduates of 2008 and trend analysis- Comparative Report for Mona, Cave Hill and St. Augustine Campuses. One year after graduation.

Wanya, C.S. (2014). Tracer study of BSIT graduates at Cagayan State University at Lal-Lo (S.Y 2010-2014). International Journal of Advanced Research in Management and Social Sciences. 5(6): 602-613. 